\title{
The Chronobiologic-Based Practical Approach to Shift Work
}

\author{
Chul-Hyun Cho ${ }^{1,2}$ and Yujin Lee ${ }^{1,2}$ \\ 'Department of Psychiatry, Korea University College of Medicine, Seoul, Korea \\ ${ }^{2}$ Chronobiology Institute, Korea University, Seoul, Korea
}

\begin{abstract}
Shift work can have a short-term, long-term adverse effect on health because it is exposed to situations that constantly disturb the circadian rhythm of the human. The purpose of this review was to examine the critical principles of determining health management plans for shift workers. Practical principles for maintaining a healthy shift work lifestyle include: maintaining circadian stability, maintaining a predictable work schedule, minimizing night shifts, and ensuring equality of working conditions. Melatonin and light therapy can be used effectively for shift work as a chronotherapeutic method. Proper caffeine intake, sleeping pills, naps, and planned meal schedules also could be a method for managing the circadian rhythm of shift workers in social life. Additionally, efforts should be made to maintain a positive work-life balance, in which work environment, workloads, overall safety, family, and social relationships are all considered. With training and basic knowledge of circadian rhythms, employers and shift workers can boost the company's profits, reduce social losses, and maintain a healthy lifestyle.

Key Words: Shift work schedule; Chronobiology disorder; Occupational health; Circadian rhythm; Biological clock disturbance

Received: August 9, 2019 Revised: September 1, 2019 Accepted: September 3, 2019

Corresponding author: Chul-Hyun Cho, MD, PhD, Department of Psychiatry, Korea University Hospital, Korea University College of Medicine, 73 Inchon-ro, Seongbuk-gu, Seoul 02841, Korea.

Tel: 82-2-920-6272, Fax: 82-2-6280-5810, E-mail: david0203@gmail.com

(a) This is an Open Access article distributed under the terms of the Creative Commons Attribution Non-Commercial License (https://creativecommons.org/licenses/bync/4.0) which permits unrestricted non-commercial use, distribution, and reproduction in any medium, provided the original work is properly cited.
\end{abstract}

\section{INTRODUCTION}

With the rapid industrialization of modern society, people's daily lives have changed. The invention of electricity has enabled the use of artificial light, which has consequently altered the industrial form and daily life [1]. The industrialization has increased both the types of occupations and the number of shifts available to workers. Shift work may be essential for security, infrastructure, and medical facilities, but in many cases, shift work is often done to increase productivity and convenience [2]. In Korea, approximately $10 \%$ of employees are shift workers. Among Korean shift workers, $50.4 \%$ work a rotating two-shift, $33.7 \%$ work a rotating three-shift, and $14.0 \%$ work a daily split shift [3]. Socioeconomic viewpoints can elucidate the necessity of shift work, though insufficient consideration and concern regarding the health effects on shift workers remain a prominent problem [4]. Shift workers may experience circadian rhythm disruption due to their shift work schedule; therefore, health impacts and consequences related to circadian rhythm disruptions should be seriously considered.

Shift work can have both short- and long-term adverse health effects, as shift workers are constantly exposed to situations that disturb the circadian rhythm [5,6] All humans have internal biological clocks, and misalignment between light-dark cycles related to the sleep-wake cycle and internal biological clock can have serious consequences. In fact, previous reports have shown fatal diseases, such as breast cancer, are more common in shift workers, and they often have endocrine, metabolism, or mental health problems [7-10]. Additionally, shift work has been shown to be associated with the increased risk of safety accidents and reduced productivity $[2,11,12]$. Therefore, both socio-economic and medical approaches to circadian rhythm management for shift workers are critical issues that cannot be overlooked.

When managing the health of shift workers, a chronobiologic approach is necessary [13]. Chronobiology investigates human internal biological clocks, including the interactions between the biological clock and external influencing factors, and the various effects of altered circadian rhythms on human health [14]. Approaching shift worker health with an understanding of human nature and basic physiology is not only valid theoretically, but such management approaches can also achieve effective results in ap- 
plication [15]. Therefore, a chronobiologic approach to the management of shift worker health is essential in the modern era.

\section{BASIC CONCEPTS}

\section{Two categories of shift work}

Shift work can be divided into two categories: fixed or rotational shift work. Fixed shift work occurs in the same pattern every day at a fixed time and usually refers to fixed shift work performed at night [16]. Rotational shift work is a change of working time at regular intervals and refers to cases where daytime and nighttime work are alternately performed in various patterns $[17,18]$. It is necessary to distinguish between the two types of shift work, because their characteristics are distinctly different. For example, fixed shift workers should be able to keep their daily rhythms as consistent as possible. Therefore, it should be possible to block sunlight during daytime hours and be exposed to a sufficient amount of light during night shifts. However, the situation is different for rotational shift workers, who must frequently change between working during daylight hours and nighttime hours. Practical approaches to light restriction and exposure should be provided in a flexible and customized manner dependent upon the work schedule rotation.

\section{Sleep-wake cycle: circadian rhythm}

The suprachiasmatic nucleus (SCN) in the brain is the mediator of the central circadian rhythm $[13,19]$. The $\mathrm{SCN}$ is entrained with the environment by various zeitgebers, such as light exposure, in order to maintain normal circadian rhythm. The central circadian rhythm also synchronizes with the peripheral circadian rhythm of each tissue or cell, so that the circadian rhythm is maintained throughout the body.

An understanding of the two-process model of sleep regulation, which is comprised of Process $\mathrm{C}$ and Process $\mathrm{S}$, is necessary when examining the sleep-wake cycle [20]. The two-process model of sleep regulation explains the two physiological processes that are required to maintain adequate sleep, as well as explains that stable sleep is maintained when the both Process $\mathrm{C}$ and Process $\mathrm{S}$ are maintained. Process $\mathrm{C}$ is defined as a circadian pacemaker, and Process $\mathrm{S}$ is defined as a homeostatic process that interacts with Process C.

\section{KEY PRINCIPLES FOR PRACTICAL APPROACHES TO PROBLEMS OF SHIFT WORK}

\section{Maintaining circadian stability}

Maintaining a stable circadian rhythm is an important part of daily human life $[21,22]$. Circadian rhythm maintenance can be increasingly critical if the types of shift work previously described are involved. Fixed shift work is preferable to rotational shift work, regardless of whether nighttime or daytime shifts are worked. Maintenance of circadian health while working a rotational shift and work rotation schedules are important to consider. Since the human intrinsic circadian rhythm is generally longer than 24 hours, shift rotation schedules should advance such that subsequent shifts begin later than the previous shifts to allow for a proper phase-shift circadian alignment $[23,24]$. This is analogous to the phenomenon that occurs when traveling, where it is easier to adapt to jet-lag when traveling from east to west compared to traveling from west to east. Employers utilizing shift work are recommended to maintain three or more shift work schedules a day. However, this requires a workforce of three or more workers per day, and trade-offs may be necessary depending on the type of work and economic conditions. When using rotating shift schedule, it is advisable to maintain the shift work schedule for 3-5 days prior to rotating the work schedule [25]. A 3-5 day rotation interval better facilitates the adaptation of the circadian rhythm to social jet-lag.

\section{Predictability of the shift work schedule}

Predictability of the rotational shift schedule is essential, as the schedule can frequently change [24]. Therefore, it would be best to agree upon set principles to form a pre-determined shift schedule [25]. Ideally, principles would account for various aspects paramount to health maintenance of shift workers, such as circadian rhythm adjustments, economic situations, the fairness of work intensity, and schedule changes. Predictable schedules have a profound effect on the daily lives of workers. Prior knowledge of schedules allows for shift workers to be well-rested and maintain social appointments.

Additionally, shift workers need a conceptual "weekend." The concept of a "weekend" can easily disappear when work schedules are altered. However, for general day-workers, "weekdays" and "weekends" are divided, and a balance of life can be achieved accordingly. A "weekend" is also necessary when scheduling shift work. The application of two consecutive days off work will improve the quality of shift work, worker satisfaction, and, ultimately, productivity.

\section{Minimum night shifts}

Along with maintaining circadian stability and predictability of schedule, another principle that must be considered is the reduction of night shifts overall [26]. This consideration does not apply to workers who work fixed night shifts. However, it is best for rotational shift workers to reduce night shift work as much as possible. In particular, it is advisable to minimize the number of consecutive nights worked, with the number of alternate night shifts worked adjusted to 2-3 days, if possible.

If several night shifts occur uninterrupted, productivity sharply decreases, and the risk of a safety accident or injury increases. According to one study, the risk of a safety accident increases by $6 \%$ on the second night worked, $17 \%$ on the third night worked, and $36 \%$ on the fourth night worked [2]. Consecutively scheduling night shifts not only places workers' health at risk, but also increases the risk of detrimental loss for a profit-seeking company. 


\section{Equality of working conditions}

It is very important to consider and accommodate equal working conditions for shift workers [27]. Equal working conditions not only help reduce the physical burdens of workers and allow them to work on equal terms, but also helps prevent psychological complaints and increase the morale of employees. This includes pursuing equal working conditions among shift workers, as well as between shift workers and general daytime workers. When shift work is scheduled, shift workers should feel able to freely express their opinions in an open atmosphere to increase discussion and maintenance of equal conditions. Night shifts can be overly concentrated, and if workers discuss their thoughts, the basic principles of healthy shift work can be executed. When considering equity with regular weekly workers, it is critical that shift workers have sufficient holidays. It is best to have a concept of 'weekend' for shift workers, and it is ideal to have an entire day off after a night shift when possible. Shift workers often are not granted the weekend given to general workers, and thus, the social life of shift workers is disturbed or diminished.

\section{TIPS TO MANAGE THE PROBLEMS OF SHIFT WORK IN SOCIAL LIFE}

\section{Work environment and workloads}

It is necessary to help shift workers stay alert while working by maintaining bright lights and cool temperatures [28]. It can be effective to provide shift workers with a strong and bright light exposure early in their scheduled shift. It is better to allocate the greatest workload or task to early in the shift, which may allow better focus and reduce the risk of safety accidents or mistakes. The working environment should provide a simple snack so that workers can maintain proper food intake. In addition, it is necessary to allow workers to stand, stretch, or walk during a task to avoid prolonged sitting.

\section{Safety in daily life}

It is necessary to guide shift workers to safety when they are outside of work. Except for cases where shift workers must drive themselves to and from work, it is helpful to have public transportation available or to encourage use of shuttle buses. Safety concerns are not only in regards to driving; the dangers of confounding the circadian rhythms amid various factors associated with safety in everyday life cannot be overemphasized.

\section{Family and social relationships}

A shift worker is prone to experience isolation from familial and social relationships, as they spend less time with family and friends [29]. Due to the shift schedule, it is not possible to always align the appointments or movements of people who follow a typical daytime schedule. Also, due to the accumulation of fatigue and lack of sleep due to shift work, it is difficult to maintain quality time with family and friends. Therefore, it is necessary for shift workers to have proper discussion about their schedule with their fam- ily. In particular, the characteristics of shift work should be explained to family members or friends, and plans should be made to spend quality time together under a predictable shift work schedule. Planning to reduce isolation in social relationships and to spend sufficient time enjoying intimacy may lead to improved work efficiency by promoting the psychological stability of shift workers.

\section{Biological methods for management}

Melatonin is known as an important chronotherapeutic agent [24]. It is used effectively for circadian rhythm disorders and jetlag problems. Since shift workers experience social "jet-lag" continuously, melatonin may be of some help in resetting the internal clock. Studies on the effectiveness of melatonin for the treatment of shift workers have been mixed. One study reported increased alertness during the subsequent night shift after melatonin $10 \mathrm{mg}$ taken before bedtime in the morning [30]. Other study showed an overall improvement in sleep quality when treated $5 \mathrm{mg}$ in the morning for six consecutive days [31]. Whereas other study showed that melatonin $6 \mathrm{mg}$ taken before daytime sleep after 4 to 6 consecutive nights of shift work was ineffective [32]. Therefore, it may be helpful for shift workers to take $5 \mathrm{mg}$ to $10 \mathrm{mg}$ of melatonin before going to bed on a shift work schedule. Sometimes, melatonin should be used with caution because it has potential side effects such as headaches, vivid dreams, nausea, and cardiovascular outcomes. Along with melatonin, light exposure (light therapy) is considered an important circadian rhythm control factor. In particular, since light exposure in the morning acts as a powerful zeitgeber, it likely also plays a powerful role in resetting the disturbed circadian rhythm [33,34]. For shift workers, it is recommended that light therapy be performed in accordance with a schedule corresponding to "morning" in the shift schedule. Caffeine (adenosine agonist) is a stimulant that is already widely used by modern people as an awakening agent [35]. Proper caffeine intake can help a person remain awake at desired times, but in turn, they may experience problems such as sleep interruption. Additionally, sleeping pills, taking a nap, and a planned meal schedule can be used as biological methods for controlling the circadian rhythm of shift workers [28,36-38].

\section{CONCLUSION}

The maintenance of a healthy circadian rhythm is a biological imperative. Maintaining a sleep-wake cycle in accordance with the inherent day-night cycle is the most natural and healthy circadian regulation for humans living on Earth. Based on this background, shift work has a negative impact on humans as it goes against the natural order and can even be fatal. In this era of industrial-oriented modern society, where increased productivity and convenience are deemed essential, it is very important to ensure that shift workers stay as safe and healthy as possible. Medical researchers, company managers, working managers, and shift workers should increase medical literacy among shift workers to this end. 
Efforts should be made to implement practical principles for maintaining health among shift workers, such as: maintaining circadian stability, ensuring predictability of shift work schedule, reduction of night shifts, and ensuring equal working conditions. Additionally, efforts should be made to ensure a healthy work-life balance through measures including: amenities in the work environment and workload allocation safety in daily life, family and social relationships, and biological methods for circadian management. With training and basic knowledge of circadian rhythms, employers and shift workers can boost the company's profits, reduce social losses, and maintain a healthy state.

\section{Acknowledgments}

This research was supported by the Brain Research Program through the National Research Foundation of Korea (NRF), funded by the Ministry of Science, ICT \& Future Planning (NRF-2016 M3C7A1914448) and ICT \& Future Planning for convergent research in Development program for convergence R\&D over Science and Technology Liberal Arts (NRF- 2017M3C1B6070978).

\section{Conflicts of Interest}

The authors have no potential conflicts of interest to disclose.

\section{Author Contributions}

Conceptualization: Chul-Hyun Cho. Funding acquisition: ChulHyun Cho. Investigation: Chul-Hyun Cho, Yujin Lee. Project administration: Chul-Hyun Cho. Resources: Chul-Hyun Cho. Supervision: Chul-Hyun Cho. Writing-original draft: Chul-Hyun Cho. Writing-review \& editing: Chul-Hyun Cho, Yujin Lee.

\section{ORCID iD}

Chul-Hyun Cho (D)

https://orcid.org/0000-0002-1663-9680

\section{REFERENCES}

1. Stevens RG. Artificial lighting in the industrialized world: circadian disruption and breast cancer. Cancer Causes Control 2006;17:501-507.

2. Folkard S, Tucker P. Shift work, safety and productivity. Occup Med 2003; 53:95-101.

3. Park J, Lee N. First Korean Working Conditions Survey: a comparison between South Korea and EU countries. Ind Health 2009;47:50-54.

4. Costa G. The impact of shift and night work on health. Appl Ergon 1996;27: 9-16.

5. Haus E, Smolensky M. Biological clocks and shift work: circadian dysregulation and potential long-term effects. Cancer Causes Control 2006;17:489-500.

6. Harrington JM. Health effects of shift work and extended hours of work. Occup Environ Med 2001;58:68-72.

7. Bøggild H, Knutsson A. Shift work, risk factors and cardiovascular disease. Scand J Work Environ Health 1999;25:85-99.

8. Davis S, Mirick DK, Stevens RG. Night shift work, light at night, and risk of breast cancer. J Natl Cancer Inst 2001;93:1557-1562.

9. Knutsson A. Health disorders of shift workers. Occup Med 2003;53:103-108.

10. Karlsson B, Knutsson A, Lindahl B. Is there an association between shift work and having a metabolic syndrome? Results from a population based study of 27485 people. Occup Environ Med 2001;58:747-752.
11. Akerstedt T, Wright KP Jr. Sleep loss and fatigue in shift work and shift work disorder. Sleep Med Clin 2009;4:257-271.

12. Huang YH, Chen JC, DeArmond S, Cigularov K, Chen PY. Roles of safety climate and shift work on perceived injury risk: a multi-level analysis. Accid Anal Prev 2007;39:1088-1096.

13. Panda S, Hogenesch JB, Kay SA. Circadian rhythms from flies to human. Nature 2002;417:329-335.

14. Panda S. The arrival of circadian medicine. Nat Rev Endocrinol 2019;15: 67-69.

15. Czeisler CA, Gooley JJ. Sleep and circadian rhythms in humans. Cold Spring Harb Symp Quant Biol 2007;72:579-597.

16. Shuib A, Kamarudin FI. Solving shift scheduling problem with days-off preference for power station workers using binary integer goal programming model. Ann Oper Res 2019;272:355-372.

17. Stock D, Knight JA, Raboud J, Cotterchio M, Strohmaier S, Willett W, et al. Rotating night shift work and menopausal age. Hum Reprod 2019;34:539548.

18. Taylor Y, Merat N, Jamson S. The effects of fatigue on cognitive performance in police officers and staff during a forward rotating shift pattern. Saf Health Work 2019;10:67-74.

19. Ralph MR, Foster RG, Davis FC, Menaker M. Transplanted suprachiasmatic nucleus determines circadian period. Science 1990;247:975-978.

20. Borbély AA. A two process model of sleep regulation. Hum Neurobiol 1982; 1:195-204.

21. Czeisler CA, Duffy JF, Shanahan TL, Brown EN, Mitchell JF, Rimmer DW, et al. Stability, precision, and near-24-hour period of the human circadian pacemaker. Science 1999;284:2177-2181.

22. Wittmann M, Dinich J, Merrow M, Roenneberg T. Social jetlag: misalignment of biological and social time. Chronobiol Int 2006;23:497-509.

23. Waterhouse J, Reilly T, Atkinson G, Edwards B. Jet lag: trends and coping strategies. Lancet 2007;369:1117-1129.

24. Smith MR, Eastman CI. Shift work: health, performance and safety problems, traditional countermeasures, and innovative management strategies to reduce circadian misalignment. Nat Sci Sleep 2012;4:111-132.

25. Scott AJ. Chronobiological considerations in shiftworker sleep and performance and shiftwork scheduling. Hum Perform 1994;7:207-233.

26. Bambra CL, Whitehead MM, Sowden AJ, Akers J, Petticrew MP. Shifting schedules: the health effects of reorganizing shift work. Am J Prev Med 2008; 34:427-434.

27. Miller JC. Fundamentals of shiftwork scheduling. Ergon Des 2008;16:13-17.

28. Monk TH. What can the chronobiologist do to help the shift worker? J Biol Rhythms 2000;15:86-94.

29. Monk TH. Coping with the stress of shift work. Work Stress 1988;2:169-172.

30. Jorgensen KM, Witting MD. Does exogenous melatonin improve day sleep or night alertness in emergency physicians working night shifts? Ann Emerg Med 1998;31:699-704.

31. Folkard S, Arendt J, Clark M. Can melatonin improve shift workers' tolerance of the night shift? Some preliminary findings. Chronobiol Int 1993;10:315320.

32. James M, Tremea MO, Jones JS, Krohmer JR. Can melatonin improve adaptation to night shift? Am J Emerg Med 1998;16:367-370.

33. Cho CH, Moon JH, Yoon HK, Kang SG, Geum D, Son GH, et al. Molecular circadian rhythm shift due to bright light exposure before bedtime is related to subthreshold bipolarity. Sci Rep 2016;6:31846.

34. Jee HJ, Cho CH, Lee YJ, Choi N, An H, Lee HJ. Solar radiation increases suicide rate after adjusting for other climate factors in South Korea. Acta Psychiatr Scand 2017;135:219-227.

35. Fredholm BB. Adenosine, adenosine receptors and the actions of caffeine. Pharmacol Toxicol 1995;76:93-101.

36. Matsumoto K, Harada M. The effect of night-time naps on recovery from fatigue following night work. Ergonomics 1994;37:899-907.

37. Samuels $\mathrm{CH}$. Jet lag and travel fatigue: a comprehensive management plan for sport medicine physicians and high-performance support teams. Clin J Sport Med 2012;22:268-273.

38. Lemmer B. The sleep-wake cycle and sleeping pills. Physiol Behav 2007;90: 285-293. 